\title{
Comprehensive one-day renal function testing in man
}

\author{
A. Z. GYÖRY1' K. D. G. EDWARDS, J. H. STEWART, AND H. M. WHYTE \\ From the Keith Kirkland Renal Unit, Medical Research Department, Kanematsu Memorial Institute, \\ Sydney Hospital, Australia
}

SYNOPSIS A comprehensive one-day renal function test consisting of a single outpatient visit lasting nine hours, with a minimum of time off work or away from home, is described in detail. Although a large number of laboratory tests are performed in one day, patients usually appreciate thoroughness, and the cost is more than offset by the saving in occupancy of hospital beds and by the early and precise diagnosis of reversible aspects of renal disease. Some aspects of improved methodology, such as the sequential determination of minimum urinary $\mathrm{pH}$, bicarbonate, titratable acid, ammonium, and total acid on a single sample using an automatic titrator, are given in detail. Clinical application of the comprehensive nine-hour renal function testing system is illustrated by the result sheet of a patient with analgesic nephropathy, who was shown in one day to have secondary severe renal failure (glomerular filtration rate $20 \%$ of normal for age and surface area), renal

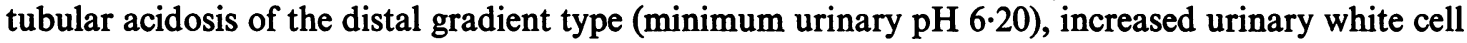
excretion rate, hyaline casts, and absence of red cell casts, consistent with a diagnosis of analgesic nephropathy and urinary tract inflammation. Normal values with $95 \%$ range for this laboratory are also given. This testing system has been found to be very useful in investigating patients with analgesic nephropathy, renal tubular acidosis, and after renal transplantation.

Clinical testing of renal function is usually considered to be complicated, highly specialized, and above all, time-consuming. To a patient it usually means several prolonged visits to a laboratory or admission to a hospital. A system was first devised in our department whereby all but a few of the renal function tests regularly used for clinical purposes were combined so as to take only nine hours to perform (Edwards, Stewart, Ashley, and Whyte, 1964). This system of one-day renal function testing has been modified and refined over the ensuing years and now includes multiple tests of glomerular, proximal and distal tubular, loop of Henle, and collecting duct functions. In addition clearance measurements of any substance can be added if so desired. The results obtained in a large number of normal volunteers over the years, when compared with published values, have shown that the simultaneous performance of several tests causes no obvious interference. In addition to its value in diagnosing renal dysfunction in indi-

${ }^{1}$ Address for reprints: Dr A. Z. Györy, Department of Medicine, Royal North Shore Hospital, St Leonards, 2065, Australia

Received for publication 4 January 1974. vidual patients, the system has already provided much useful pathophysiological information about disease states including renal tubular acidosis (Györy and Edwards, 1968), analgesic nephropathy related to abuse of aspirin, phenacetin, and caffeine combinations (Steele, Györy, and Edwards, 1969; Steele and Edwards, 1971) or to aspirin therapy (Edwards, Schapel, Jeremy, and Steele, 1972; Schapel, Edwards, Jeremy, and Steele, 1972), and renal transplantation (Györy, Stewart, George, Tiller, and Edwards, 1969).

The following is a detailed description of the time sequence of the test, the methods used, and the results obtained in normal volunteers. Comments on procedure and discussion of the comparative value of the most important functional tests are included. The list of instructions to the patients is followed by the detailed time sequence of the test. Not included is a short summary of this time sequence set out as a worksheet for the nursing sister running the test. Actual times of collections and operations carried out are entered on this sheet which is similar to table 4 of the original presentation (Edwards et al, 1964). 


\section{Procedure}

\section{INSTRUCTIONS TO PATIENTS}

No drugs or patent medicines should be taken for 48 hours preceding the test. However, in cases of severe hypertension, clonidine or guanethidine may be continued.

Breakfast on the day of the test should consist of two or three slices of toast thinly buttered, with jam or marmalade, and a fruit drink. Meat, egg, milk, alcohol, coffee, or tea are forbidden on the day of the test.

Apart from the water taken with the ammonium chloride, no more than two glasses $(360 \mathrm{ml})$ of water are allowed during the test. Tea or coffee and smoking are prohibited. A light lunch, consisting of salad, a thin sliver of meat, and some bread, is provided at the hospital.

A breakfast is essential to avoid the development of starvation lactic acidosis which would upset subsequent lactic acid measurement as well as interfere with uric acid elimination and thus give falsely high serum uric acid values.

\section{TIME SEQUENCE}

The patient arrives in the ward at 8 am sharp. 8.00-8.15 am

The patient's height and weight are measured and surface area calculated from the table of Du Bois and Du Bois (Diem and Lentner, 1970).

Venous blood is taken. Twenty $\mathrm{ml}$ of clotted blood is taken to the Biochemical Laboratory for determination of electrolytes, urea, specific gravity, calcium, magnesium, cholesterol, alkaline phosphatase, albumin, globulin, total protein and electrophoretic pattern.

Five $\mathrm{ml}$ in EDTA is sent to the Haematology Laboratory and $15 \mathrm{ml}$ of clotted blood to the Renal Laboratory (serum I) for creatinine determination.

Arterialized capillary blood is taken by the Renal Laboratory for blood gas analysis.

Five units of vasopressin tannate in oil (Parke Davis) is given subcutaneously after careful shaking and dispersing of solid material in the ampoule. 8.15-8.30 am

A clean midstream specimen of urine is taken for microscopic examination of deposit and culture in the Bacteriology Department and Renal Laboratory.

The bladder is emptied completely and the time is noted on (1) the work sheet and (2) the first collection measuring cylinder.

\subsection{5-9.15 am}

Ammonium chloride $0 \cdot 1 \mathrm{~g} / \mathrm{kg}$ body weight to nearest $0.5 \mathrm{~g}\left(60-70 \mathrm{mM} / \mathrm{m}^{2} \mathrm{SA}\right)$ is commenced; ammonium chloride is to be taken over one hour irrespective of the number of capsules and patients may have a bite of toast or biscuit if nausea ensues.

The time taken over ingestion of ammonium chloride is noted and if capsules are vomited the Renal Laboratory is to be informed and the fact should be recorded on the work sheet.

\section{$11.45-12.00 \mathrm{pm}$}

Three and a half hours after the beginning of ingestion of ammonium chloride, the bladder is emptied completely into the first collection cylinder $\left(U_{1}\right)$; the time is noted on (1) the work sheet, (2) the first collection cylinder, (3) the second collection cylinder.

The specimen is sent to the Renal Laboratory as quickly as possible for determination of white cell excretion rate, creatinine, qualitative urine testing, and osmolality.

\section{$1.30 \mathrm{pm}$}

Arterialized capillary blood is taken by the Renal Laboratory for blood gas analysis.

\section{$2.30 \mathrm{pm}$}

A dose of phenolsulphonphthalein (PSP) is prepared in a 10-ml calibrated Hamilton syringe according to surface area (18 $\mathrm{mg}$ per one square metre surface area).

\section{$2.40 \mathrm{pm}$}

Two hours and 40 minutes after the beginning of the second collection period venous blood is collected by medical officers.

Ten $\mathrm{ml}$ of clotted blood is sent to the Biochemistry Laboratory for determination of uric acid and inorganic phosphorus. Twenty $\mathrm{ml}$ of clotted blood is sent to the Renal Laboratory (serum II) for determination of citrate, lactate, creatinine, and osmolality or other measurements.

\section{$2.45 \mathrm{pm}$}

Phenolsulphonphthalein is injected over two minutes and time is noted after one minute has elapsed.

\section{$3.00 \mathrm{pm}$}

Exactly 15 min after noted PSP time patient must empty bladder completely $\left(\mathrm{U}_{2}\right)$ directly (through filter funnel in case of females) into measuring cylinder with paraffin; it is stoppered tightly, and returned immediately to the Renal Laboratory for measurement of creatinine, PSP, osmolality, urinary $\mathrm{pH}$, bicarbonate, titratable acid, ammonia, citrate and lactate, and some is sent to the Biochemistry Laboratory for determination of inorganic phosphorus and uric acid. The time is noted on (1) work sheet, (2) second measuring cylinder, (3) third measuring cylinder.

\section{$4.45 \mathrm{pm}$}

Exactly two hours after noted PSP time, patient must empty bladder completely into third collection cylinder $\left(\mathrm{U}_{3}\right)$, and this is taken to the Renal Laboratory for determination of osmolality, PSP, and 
creatinine; the time is noted on (1) work sheet, (2) third measuring cylinder.

The patient is discharged.

The success of the entire test undoubtedly depends on the interested cooperation of a well trained nursing sister and technical assistant. They are responsible for strict observation of all timed urine collections and supervision of complete bladder emptying during the collections. All further comments on the procedure imply that both the nursing sister as well as the technician fully understand the mechanisms involved.

If vomiting ensues during the first half of ammonium chloride ingestion, the full dose is repeated and time is counted from the time of taking the new load. If vomiting occurs in the second half hour, half the dose is administered again and timing is unaltered. If the first blood gas analysis shows the patient to be alkalotic (whole blood base excess greater than +3 m-equiv/1) an extra half dose of ammonium chloride is given.

It is important to observe the slow injection of the PSP, since rapid injection will present the kidney with a dose greater than the tubular maximum for secretion and relatively less will be eliminated by secretion than by filtration.

The person giving the vasopressin injection has to be thoroughly acquainted with the fact that the insoluble and visible reddish particles in the oily injection are the vasopressin and that these must be injected. This can be ensured by thoroughly warming and shaking the ampoule under constant visual control.

\section{Laboratory Methods}

The urinary white cell excretion rate is estimated on the first three-hour urinary collection by centrifuging a $10 \mathrm{ml}$ aliquot of well mixed urine for 10 minutes at $2000 \mathrm{rpm}$. All except $0.9 \mathrm{ml}$ of the supernatant is discarded, volume is filled up to the $1 \mathrm{ml}$ mark with glacial acetic acid, and mixed well again. The number of intact white cells are then counted in 160 of the small squares of a FuchsRosenthal chamber $(0.2 \mathrm{~mm}$ space width). The number thus obtained is multiplied by 3000 and the urinary minute volume (V) to obtain cell excretion rate in cells per hour. Normal by this technique is less than $10^{5}$ white cells/hr (Houghton and Pears, 1957). Microscopy for other formed elements as well as for red and white cells (to confirm the white cell excretion rates) is also performed immediately on a fresh specimen voided under sterile conditions at the commencement of the first collection period. All of this except for $10 \mathrm{ml}$ is sent to the Bacteriology Department for culture.
The $10 \mathrm{ml}$ aliquot is centrifuged at $2000 \mathrm{rpm}$ for four minutes in a graduated centrifuge tube, $9.5 \mathrm{ml}$ discarded, and the sediment well mixed. The entire field of 16 large squares $(0.0032 \mathrm{ml})$ of a FuchsRosenthal chamber is searched for casts, and 16 small squares $(0.0002 \mathrm{ml})$ are searched for intact white and red cells. A single cast, more than 8 white cells $\left(2 / \mathrm{mm}^{3}\right)$ or more than 2 red cells $\left(0.5 / \mathrm{mm}^{3}\right)$ are regarded as abnormal. These are $\vec{\circ}$ maximum numbers and if daily urine flows are greater than $1000 \mathrm{ml}$ lower numbers could be $\vec{\sigma}$ abnormal. These normal limits correspond to the normal values obtained for white cell excretion rates by the method of Houghton and Pears (1957) rather than those by the Addis count. The latter technique produces lower values (Lippman, 1967) probably because of lysis of cells in the collection bottle during the 24-hour period.

Serum sodium, potassium, chloride, $\mathrm{CO}_{2}$-combining power, blood urea nitrogen, creatinine, inorganic phosphorus, uric acid, calcium, albumin, globulin, and serum alkaline phosphatase are measured by standard autoanalytical procedures. Serum magnesium is measured by atomic absorption spectrophotometry and specific gravity by floatation in copper sulphate solutions. Blood is also examined by standard haematological procedures in the Haematology Department.

Urinary creatinine and true creatinine of sera $I$ and II, measured by the method described by Edwards and Whyte (1958), are used for the determination of creatinine clearance. A Versatol standard for recovery is always included in the series as quality control and when there is occasional variation in excess of $10 \%$ of this, serum values are corrected accordingly.

Blood gas determinations are performed by the micro-equilibrium method of Siggaard-Andersen, Engel, Jorgensen, and Astrup (1960) on arterialized capillary blood at $37.5^{\circ} \mathrm{C}$ using Radiometer $\frac{7}{O}$ equipment. Blood is obtained from a finger prick with a number 11 surgical blade, the hand being $N$ prewarmed for 10 minutes to assure rapid and free $N$ flow of blood.

Determinations of urinary bicarbonate and titratable acid are by a titrimetric method (Györy and Edwards, 1967). Urinary ammonia excretion is measured by an extension of this technique adapted $\stackrel{\odot}{\infty}$ from Jørgensen (1957). At the end of the bicarbonate and titratable acid titration to a pH of 7.40 an additional $1.0 \mathrm{ml}$ of $1 \mathrm{M} \mathrm{HCl}$ is added followed by $25 \mathrm{ml}$ of $16 \%$ formaldehyde previously adjusted to a pH of 7.40. The urine is again titrated to a $\cong$ pH of 7.40 (fig 1). Calculations are similar to that for the bicarbonate/titratable acid moieties, 8 but in the case of ammonia, volume B + volume 


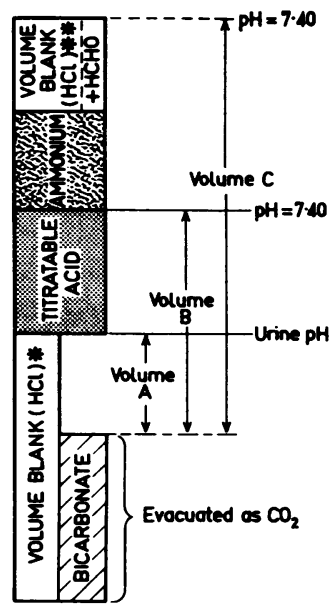

$\mathrm{pH}<7 \cdot 40$

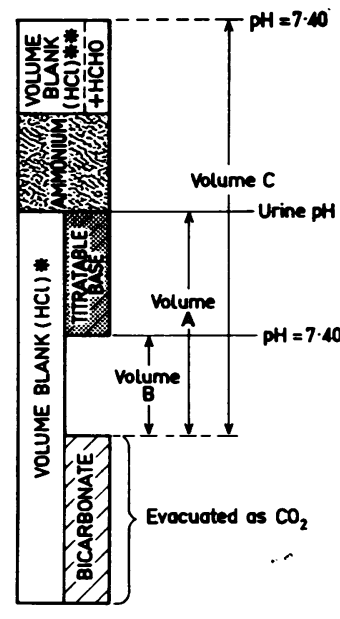

$\mathrm{pH}>7 \cdot 40$
* Volume of $\mathrm{HCl}$. used here depends on initial urinory $\mathrm{pH}$ * * Volume of HCl. used is always $1.00 \mathrm{ml}$.

Fig 1 Graphic representation showing the sequential titrimetric method of determining urinary acid-base parameters.

for blank of $1.0 \mathrm{ml} \mathrm{HCl}$ are subtracted from the final volume or volume $C$ (figure 1). An important point relevant to this method is that all precautions should be taken to prevent loss of $\mathrm{CO}_{2}$ from the urine as this will raise the $\mathrm{pH}$ of the sample and lead to an overestimation of the bicarbonate content by an appreciable amount. All urines for bicarbonate determinations should therefore be collected under paraffin.

Phenolsulphonphthalein (PSP) is determined spectrophotometrically by alkalinizing $0.2 \mathrm{ml}$ urine with $4 \mathrm{ml}$ of $0.66 \mathrm{M} \mathrm{NaOH}$ and reading at $560 \mathrm{~m} \mu$. The optical density thus obtained is multiplied by 13.125 and the total volume of the urinary specimen and the result expressed as a percentage of the injected dose (Healy, Edwards, and Whyte, 1964).

Urine and serum osmolalities are measured on an Advanced Instrument Inc. Osmometer model 63-31 calibrated to read directly. However, standards with osmolalities similar to the sample are also measured and corrections made accordingly.

\section{Discussion}

The nine-hour renal function test more than adequately defines glomerular, proximal, distal tubular, and collecting duct functions under reasonably standardized conditions during the working hours of the day. The special value of the system lies in the fact that these functions are defined simultaneously thus allowing for accurate separation of each tubular function from the effects of glomerular filtration. It does not give information on the intricate mechanisms of sodium and potassium excretion gained by more protracted and specialized balance studies. Nor does it give information on renal plasma flow, except indirectly by the PSP excretion test. Normal values for the system have been established on normal volunteers without any history of renal, cardiac, or hepatic disease. The $95 \%$ limits of these normal values are given in the result sheet, and mean normal values can be obtained by calculating the arithmetic mean of these limits. The example shown in fig 2 highlights especially well the value of the white cell excretion rate measurement and examination of a freshly voided specimen as important adjuncts to the diagnostic value of the system (Lippman, 1967).

The glomerular filtration rate (GFR) is usually measured by one of two techniques. The first, employed here, makes use of the clearance of endogenous creatinine, a substance with a naturally constant plasma level due to its steady release from skeletal muscle (Borsook and Dubnoff, 1947; Edwards, 1959). There are two potential hazards in the use of creatinine as a measure of the glomerular filtration rate. The first relates to the specificity of the estimation in plasma in which other substances, especially glucose, acetoacetate, or drugs, give the same colour reaction as creatinine. This is overcome by estimating true creatinine as against other chromogens (Edwards and Whyte, 1958). The second relates to the possibility of its secretion by renal tubules which has not yet been satisfactorily settled, even with micropuncture techniques. The majority of |publications dealing with simultaneous inulin and endogenous creatinine clearances in man show close agreement but a constant discrepancy such that the latter is in excess of the former by approximately 5 to $10 \%$ (Healy, 1968). The second alternative method, and the more widely used in physiological research, is the estimation of the clearance of a substance foreign to the organism needing constant infusion. Inulin, a polysaccharide of plant origin, has been widely employed for this purpose since its inaugural use by Homer Smith. The main disadvantages in the use of inulin result from the fact that its accuracy as a measure of the GFR depends largely on establishing a constant plasma concentration during the measurement, otherwise over- or underestimations readily occur. This can become difficult in patients with impaired renal function of unknown degree. It should 


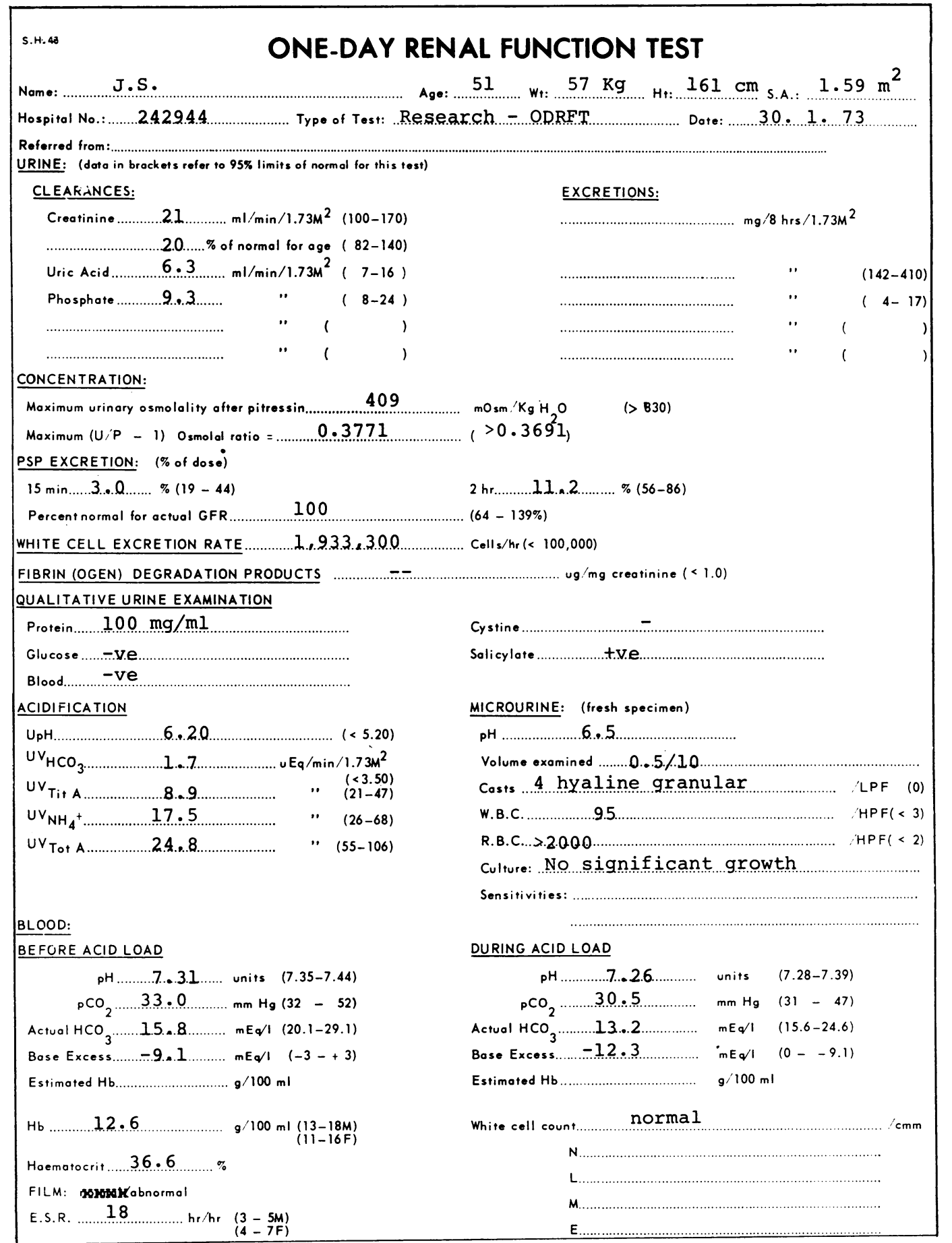

Fig 2 Result sheet showing results obtained in a patient, J.S. Note particularly that in this patient both the abnormal PSP and concentration tests, when 'corrected' for the low glomerular filtration rate become 'normal' and therefore $§$ showed that there was no specific defect in these functions. These, in addition to the results of the microurine with absence of red cell casts but presence of hyaline granular casts and an increased white cell excretion rate indicate that this patient's condition most probably originated from pyelonephritis and/or analgesic abuse, both of which $\stackrel{2}{\partial}$ 


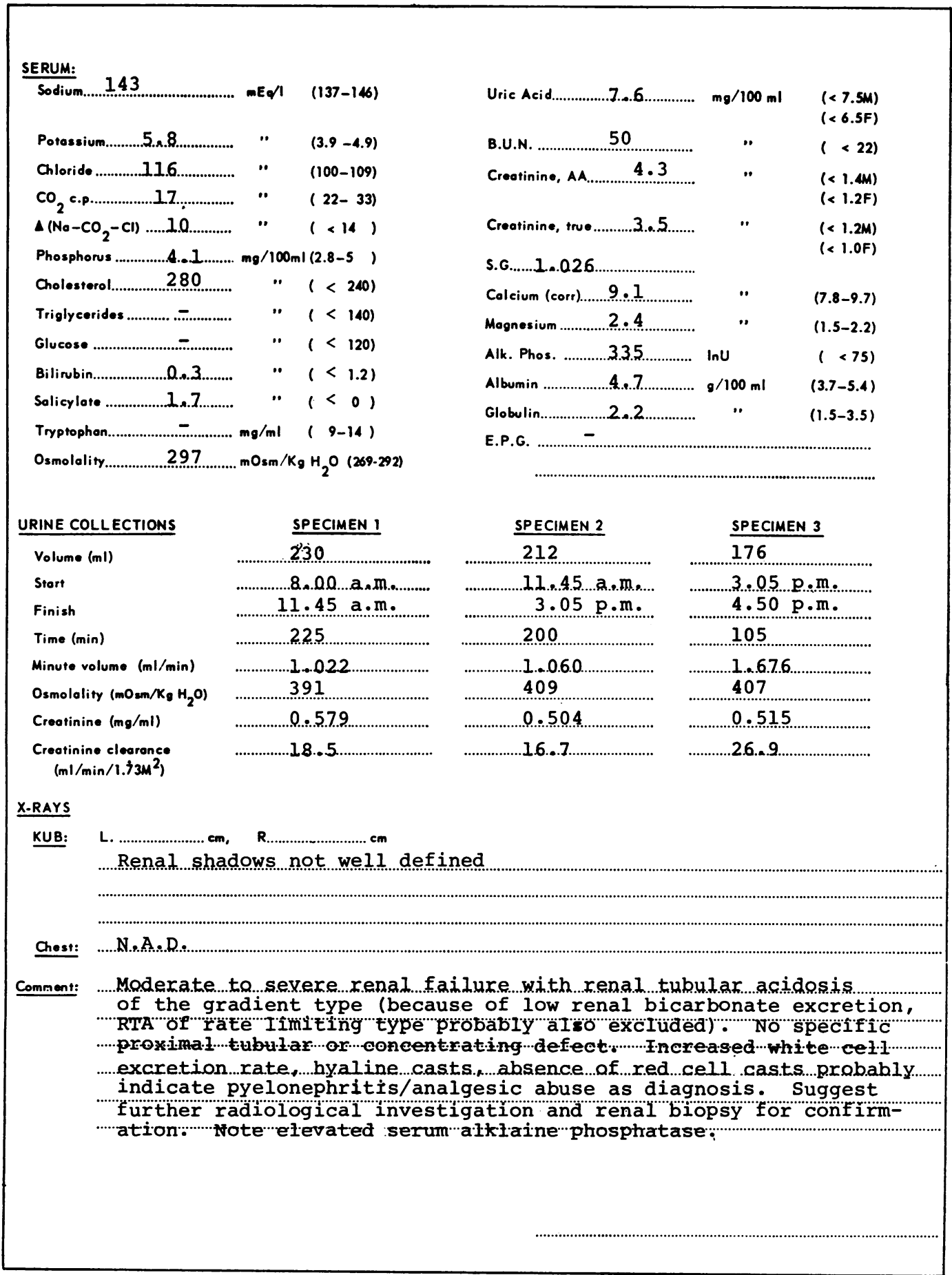

were confirmed from the history. Note also that, because the plasma actual bicarbonate had been lowered by $2 \cdot 6$ $\mathrm{mM} / \mathrm{l}$ following acid loading to below a possibly low renal bicarbonate threshold, but minimum urinary $\mathrm{pH}$ remained at 6.20 units, the gradient type of renal tubular acidosis can be diagnosed. It does not, however, exclude the simultaneous presence of the bicarbonate wasting or rate-limited type of $R T A$, the presence of which should be suspected if systematic acidosis is difficult to correct with normal doses of bicarbonate. 
also be pointed out that neither the sieving characteristics of human glomerular capillary membranes with regard to the differences in molecular weight between inulin $(\sim 5000)$ and creatinine (113) nor the absolute lack of tubular secretion or reabsorption of inulin have been precisely defined. These three factors will determine whether the test substance shows the 'clearance of water and salts' which are of actual importance to clinicians. Not even in the rat where most of the micropuncture work has been performed is there unanimity of opinion on the adequacy of inulin as a measure of the glomerular filtration rate (Berglund, Engberg, Persson, and Ulfendahl, 1969). Because the differences between true endogenous creatinine and inulin clearances are small and usually lie within the limits of the experimental errors of the techniques, and because of the overwhelming simplicity of the creatinine clearance method, the latter has been the preferred test for clinical use. True endogenous creatinine clearances obtained in normal volunteers during the first and second three-hour collections of the one-day renal function test were $131 \pm 21.9 \pm$ $4.9($ mean $\pm S D \pm S E)$ and $132 \pm 19.7 \pm 4.2 \mathrm{ml} /$ $\mathrm{min} / 1 \cdot 73 \mathrm{M}^{2}$ at urine flows of approximately $1 \mathrm{ml} / \mathrm{min}$. These results show that two to three-hour collection periods at low urine flow rates can be use to measure the glomerular filtration rate accurately when adequate supervision is available. Further information about the normality of a particular GFR can be gained by comparing it with the expected normal for age (Davies and Shock, 1950) which allows for the diagnosis of borderline abnormalities, expecially in the elderly.

The acid loading test as performed here is a simplification of the 'short' test introduced by Wrong and Davies (1959) and is based upon their observation that a single acid load of ammonium chloride has its maximum effect between three and six hours after ingestion. Parameters of acid excretion vary according to body surface area and have to be corrected for (Györy and Edwards, 1968; Tannen, 1971). Comparison with the values obtained by Wrong and Davies (1959) show a close correlation: minimum urinary pH $4.85 \pm 0.03$ (mean \pm SE) and $4.81 \pm 0.07$; titratable acidity $34.2 \pm 1.4$ and $37.9 \pm 3.3$; urinary ammonium $47.0 \pm 2.2$ and $50.4 \pm 4.0 \mu \mathrm{mo}: / \mathrm{min}$ for the present study and that of Wrong and Davies (1959) respectively. It is important to check whether the urine titrated for acid excretion is not infected with Proteus vulgaris because this organism will rapidly split urea into ammonia and bicarbonate altering urinary $\mathrm{pH}$ within an hour even at room temperature (Györy, 1969). Since these changes already occur in the bladder, no acid excretion should be measured in the presence of this organism even if antibiotics are added to 24-hour urine collecting bottles (Cochran, Peacock, Smith, and Nordin, 1968).

Measuring arterialized capillary blood gases before and during acid loading is essential for the correct diagnosis of renal acid-base disturbances. First, they will show preexisting respiratory or metabolic disturbances which would complicate the test, and secondly, they allow a certain degree of differentiation between so-called 'proximal - rate limited or bicarbonate-wasting' type and the 'distal - gradient limited or classic' type of renal tubular acidosis. In both, the patients will be acidaemic and have an alkaline urine $\mathrm{pH}$. In the former, because a defective and reduced rate of proximal tubular bicarbonate reabsorption, allowing too much bicarbonate to escape the proximal tubule, is thought to flood the normally functioning distal sites. In the latter, there is a distal defect in setting up maximum gradients for hydrogen ions while proximal bicarbonate reabsorption is entirely normal. The bicarbonate wasters 'coast' along at their abnormally low proximal bicarbonate-reabsorbing capacity and should their plasma bicarbonate level be lowered still further, such as by an acid load, the lower filtered amount of bicarbonate is now capable of full reabsorption allowing their distal sites to establish normal maximum $\mathrm{pH}$ gradients with normal minimum urinary $\mathrm{pH}$ levels. In the gradient type of defect, because the bicarbonate reabsorbing capacity is normal, any further lowering of the amount delivered to proximal sites will not affect the distal defect which will still show an abnormally high $\mathrm{pH}$. These latter in fact never 'waste' bicarbonate and their urinary $\mathrm{pCO}_{2}$ and bicarbonate contents are indeed lower than in normals at the same urinary $\mathrm{pH}$ (Pak-Poy and Wrong, 1960). When both conditions coexist only bicarbonate infusion studies will definitely demonstrate the simultaneous existence of bicarbonate wastage. There is a third group of patients who, although they have the gradient defect, are not acidaemic and most of the time show no systemic acidosis. They are said to have an incomplete renal tubular acidification defect (IRTAD). That is, although their minimum urinary $\mathrm{pH}$ values arealways abnormally high, these patients do not become acidotic, because they compensate by excreting abnormally high amounts of ammonia (Wrong and Davies, 1959). They do, however, suffer most of the complications of the complete type such as nephrocalcinosis and renal calculi and their recognition is therefore of importance. This is especially so in view of the fact that it is these patients who will most probably benefit from ethacrynic acid therapy (Györy and Edwards, 1971). It is also important to 
measure actual changes produced in blood acidbase parameters by ammonium chloride ingestion for another reason. This is to check whether satisfactory acidification (whole blood base excess > $-2.5 \mathrm{mM} / \mathrm{l}$ ) of the blood has been produced. We have observed that a small number of patients although having ingested the ammonium chloride without vomiting showed no change in blood acid-base parameters and no acidification of the urine. We have no explanation for this phenomenon but recognition of it is of obvious importance. In such cases, the test is repeated with twice the dose of ammonium chloride.

Virtually no specific, clinically functional and reliable tests of proximal tubular function exist. The 15-minute PSP excretion test, when performed accurately, although not entirely satisfactory, does offer some means whereby proximal tubular function can be quantitated. Phenolsulphonphthalein is secreted by proximal tubules but its renal elimination is complicated by partial albumin binding and a relatively low affinity for its proposed transepithelial carrier molecule. Its maximum secretory rate and renal extraction ratio is thus only approximately $50-60 \%$ of that of paraminohippurate (PAH). The disadvantages which accrue from this are that drugs, such as sulphonamides, penicillin, salicylate, and diuretics, can displace PSP from albumin and alter its excretion rate. Also, protein abnormalities such as hypoalbuminaemia or myeloma protein can increase or decrease its excretion rate respectively. In addition, its maximum tubular secretory rate is approached at plasma levels above $1 \mathrm{mg} / 100 \mathrm{ml}$ (Healy, Edwards, and Whyte, 1964) and these can easily be reached if the doses used here are administered too rapidly. In this case relatively more will be excreted by filtration in one passage through the kidney than by secretion and the test therefore becomes more a measure of glomerular filtration than of proximal tubular function. Injection rates of one or two minutes avoid these errors. Phenolsulphonphthalein does have one advantage over PAH, namely, that due to its low affinity for its carrier. Because of this, the cellular mechanism for PSP secretion can be more easily disturbed, and its excretion rate is therefore a more sensitive test of cellular function but a less sensitive one of renal blood flow (Heidland, 1968). With these reservations in mind, the test still offers information not obtainable by other means. The observation that its excretion bears a highly positive linear relationship to glomerular filtration (Healy et al, 1964; Healy, 1968) has to be considered when testing patients with reduced filtration rates. Because only about $6 \%$ of the excreted PSP is derived through filtration (Heidland, 1968), its correlation with the glomerular filtration rate indicates that in those patients with a reduced rate there is a concomitant reduction in proximal tubular secretion of phenolsulphonphthalein. In other words, the glomerular - proximal tubular balance is maintained. Any discrepancy between the two, therefore, if statistically quantitated, will give a measure of specific tubular abnormality. Here, advantage is taken of this relationship between glomerular filtration and the 15-minute PSP excretion. A prediction is made about the glomerular filtration rate from the PSP excretion and this is compared to the rate actually measured GFR as a percentage. If the values lie outside the $95 \%$ confidence limit of the normal (see result sheet) a 'glomerular-tubular imbalance' exists which could be due to alteration in renal blood flow, cellular metabolism, or transport.

Concentrating ability of the kidney under maximum antidiuretic hormone (ADH) activity is intimately connected to urine flow and load of osmotically active particles. These variables are of no consequence when testing patients with normal GFR and absence of osmotic diuretics, but will interfere in those with a reduced GFR. Maximum urine to plasma (U/P) osmotic ratios under maximum concentrating states (endogenous or exogenous ADH) will fall exponentially towards unity when osmotic load and therefore urine flows are increased. Free water reabsorption, that moiety of the filtered water accompanying the osmotic load (clearance of osmoles $=\mathrm{U}_{\text {osm }} \times \mathrm{V} / \mathrm{P}_{\text {osm }}$ ) which escapes excretion and which therefore must have been reabsorbed is calculated by subtracting the volume of urine excreting the osmotic load per minute $(\mathrm{V}=$ minute volume) from that volume in which the osmotic load was filtered, ie, Uosm $\times$ V/Posm $-\mathrm{V}$ or $\mathrm{V}\left(\mathrm{U} /\right.$ Posm $_{-1}$ ). When the kidneys are concentrating this quantity will asymptotically approach a maximum - the so-called maximum free water absorption $\left(\mathrm{T}_{\mathrm{m}} \mathrm{C}_{\mathrm{H}_{2} \mathrm{O}}\right)$ under increasing osmotic loads and therefore increasing urine flows. This set of circumstances also exists in concentrating kidneys without extra exogenous osmotic loads but with a reduced glomerular filtration rate. Each nephron of these kidneys is assumed to be undergoing osmotic diuresis in proportion to the reduction of GFR. To eliminate this effect of GFR upon maximum concentrating ability and to see whether patients had specific concentrating defects or had a reduced maximum urinary osmolality only due to the reduced glomeruler filtration rate, investigators in the past have corrected $\mathrm{TC}_{\mathrm{H}_{2} \mathrm{O}}$ for the existing $\mathrm{C}_{\mathrm{O} \text { sm }}$ by drawing a regression line between this and $\mathrm{TC}_{\mathrm{H}_{2} \mathrm{O}}$. Regression lines, however, cannot be drawn statistically between two variables each containing part of the same variable. This was overcome here by 
examining the relationship between the logarithm of the maximum (U/Posm - 1) under exogenous ADH and urine flow corrected to $100 \mathrm{ml}$ GFR (corrected for surface area). The result is a highly linear relationship (Györy et al, 1969) with statistically well defined limits. The existence of this relationship under our test conditions implies that even without an exogenous osmotic load the same mechanism is responsible for the variation in urine flow, namely, variation in osmotic load. In our normal volunteers, urine flow varied maximally up to $1.5 \mathrm{ml} / \mathrm{minute}$, and, since this is usually exceeded in patients with reduced GFR, data were obtained from the literature on human volunteers undergoing exogenous osmotic loading such that urine flows approached $10 \mathrm{ml}$ per minute (Steele et al, 1969). The two regression lines thus obtained were not different from each other $(P>0.70)$. The correlation coefficient for the composite line was -0.967 (P $<0.001$ ) (Steele et al, 1969). For urine flows of less than 1.5 per minute, the regression line obtained from the one-day renal function test volunteers is used and gives a lower limit of the normal 'maximum (Uosm/Posm - 1)' as equal to the antilog of 0.3892 $0.1413 \times V \times \frac{100}{G F R}\left(\mathrm{ml} / \mathrm{min} / 1 \cdot 73 \mathrm{M}^{2}\right)$. For urine

flows greater than $1.5 \mathrm{ml} / \mathrm{min}$ the lower confidence limit of the composite line is used, which is equal to the antilog of $0.2672-0.1103 \times \mathrm{V} \times \frac{100}{\mathrm{GFR}}(\mathrm{ml} /$ $\left.\min / 1 \cdot 73 \mathrm{M}^{2}\right)$. These confidence limits allow for the following differentiations: for example, patient D.C., aged 46, had a maximum urinary osmolality of 416 and serum osmolality of $282 \mathrm{mOsm} / \mathrm{kg}$ of water at a urine flow of $0.52 \mathrm{ml} / \mathrm{min}$ and a creatinine clearance of $39 \mathrm{ml} / \mathrm{min} / 1 \cdot 73 \mathrm{M}^{2}$. Her 'maximum (U/P - 1)' was 0.475 , whereas the lower limit of the normal for her urine flow should be 1.581 thereby indicating that she had a specific inability to concentrate her urine, in excess of the defect caused by the reduced GFR. This patient also had an increased white cell excretion rate and a urinary tract infection (positive bacterial culture) which probably contributed to the specific concentrating defect. Another patient, J.H., aged 64, had a maximum urinary osmolality of 445 and serum osmolality of 308 $\mathrm{mOsm} / \mathrm{kg}$ of water at a urine flow of $1.43 \mathrm{ml} / \mathrm{minute}$ and a creatinine clearance of $25 \mathrm{ml} /$ minute $/ 1 \cdot 73 \mathrm{M}^{2}$ surface area. His maximum (Uosm/Posm -1) was 0.440 whereas the lower limit of normal (95\% confidence limit) was 0.430 ; in other words, he was just at the lower limit of normal and probably did not have a significant concentrating defect apart from that caused by the reduced GFR (see also result sheet). It should be noted that the relationship thus described reduces to one between the logarithm of the 'maximum (Uosm/Posm -1)' against the plasma: urine concentration ratio of creatinine which is independent of the urine flow and therefore of accurate urine collections. It should also be noted that physiologically a non-specific reduction of maximum urinary osmolality due to a reduced GFR still implies a water-losing state. This manipulation does, however, give one a further specific tool in defining abnormalities of either the ascending limbs of the loop of Henle and/or the collecting ducts.

The authors wish to acknowledge the devoted and expert help given by the sisters of Ward 17, especially Penny Wells, Thelma Jones, and Ruth Timbs, in supervising the test and the technical assistance of a number of people, especially Ann Stuckey, BSc, and Ted Hung, AAIMLT, who had performed part of the test regularly over a number of years. Grateful acknowledgement is also due to the willing help given by the staff of the Biochemistry, Haematology, Bacteriology, and the Radiology Depatrments of Sydney Hospital, and the numerous volunteers who acted as normal controls. During the years also the support of the NH and MRC is gratefully acknowledged.

\section{References}

Berglund, F., Engberg, A. M., Persson, E., and Ulfendahl, H. (1969) Renal clearances of labelled inulin (inulin-carboxyl-14C inulin-methoxyl- ${ }^{3} \mathrm{H}$ ) and a polyethylene glycol (PEG1000) in the rat. Acta physiol. scand., 76, 458-462.

Borsook, H., and Dubnoff, J. W. (1947). The hydrolysis of phosphocreatine and the origin of urinary creatinine. J. biol. Chem. 168, 493-510.

Cochran, M., Peacock, M., Smith, D. A., and Nordin, B. E. C. (1968). Renal tubular acidosis of pyelonephritis with renal stone disease. Brit. med. J., 2, 721-729.

Davies, D. F., and Shock, N. W. (1950). Age changes in glomerular filtration rate, effective renal plasma flow and tubular excretory capacity in adult males. J. clin. Invest., 29, 496-507.

Diem, K., and Lentner, C., Eds. (1970). Documenta Geigy Scientific Tables, 7th ed. Geigy, Basle.

Edwards, K. D. G. (1959). Creatinine. Its usefulness in health and renal disease as a measure of muscle mass, total body water and $N$ glomerular filtration rate. MD Thesis, University of Sydney.

Edwards, K. D. G., Schapel, G. J., Jeremy, R., and Steele, T. W. (1972). Possible nephrotoxicity of aspirin in rheumatoid arthritis. Med. J. Aust., 1, 492.

Edwards, K. D. G., Stewart, J. H., Ashley, B. C. E., and Whyte, H. M. (1964). One-day renal function tests. Proc. Aust. Ass. clin. Biochem., 1, 101-105.

Edwards, K. D. G., and Whyte, H. M. (1958), The measurement of creatinine in plasma and urine. Aust. J. exp. biol., med. Sci., 36, \& 383-394.

Györy, A. Z. (1969). Studies of renal acid-base regulation in man and the rat. MD Thesis, University of Sydney.

Györy, A. Z., and Edwards, K. D. G. (1967). Simultaneous titrimetric determination of bicarbonate and titratable acid of urine. Aust. J. exp. biol. med. Sci., 45, 141-147.

Györy, A. Z., and Edwards, K. D. G. (1968). Renal tubular acidosis: a family with an autosomal dominant genetic defect in $O$ renal hydrogen ion transport, with proximal tubular and collecting duct dysfunction and an increased metabolism of citrate and ammonia. Amer. J. Med., 45, 43-62. 
Györy, A. Z., and Edwards, K. D. G. (1971). Effect of mersalyl, ethacrynic acid and sodium sulphate infusion on urinary acidification in hereditary renal tubular acidosis. Med. J. Aust., 2, 940-945.

Györy, A. Z., Stewart, J. H., George, C. R. P., Tiller, D. J. and Edwards, K. D. G. (1969). Renal tubular acidosis, acidosis due to hyperkalaemia, hypercalcaemia, disordered citrate metabolism and other tubular dysfunctions following human renal transplantation, Ouart. J. Med., 38, 231-254.

Healy, J. K. (1968). Clinical assessment of glomerular filtration rate by different forms of creatinine clearance and a modified urinary phenolsulphonphthalein excretion test. Amer. J. Med., 44, 348-358.

Healy, J. K., Edwards, K. D. G., and Whyte, H. M. (1964). Simple tests of renal function using creatinine phenolsulphonphthalein and pitressin. J. cli. Path., 17, 557-563.

Heidland, A. (1968). Klinisch-experimentelle Untersuchungen über den Renalen Phenolsulfonphthalein-Transport. Arch. klin. Med., 214, 163-186.

Houghton, B. J., and Pears, M. A. (1957). Cell excretion in normal urine. Brit. med. J., 1, 622-625.

Jørgensen, K. (1957). Titrimetric determination of the net excretion of acid/base in urine. Scand. J. clin. Lab. Invest., 9, 287-291.

Lippman, R. W. (1967). Urine and the Urinary Sediment. Thomas, Springfield, Illinois.

Pak-Poy, R. K., and Wrong, O. (1960). The urinary $\mathrm{pCO}_{2}$ in renal disease. Clin. Sci., 19, 631-639.

Schapel, G. J., Edwards, K. D. G., Jeremy, R., and Steele, T. W. (1972). Association between aspirin therapy and nephrotoxicity in rheumatoid arthritis. (Abstr.) Aust. N.Z. J. Med., 2, 427.

Siggaard-Andersen, O., Engel, K., Jørgensen, $K$., and Astrup, P. (1960). A micromethod for determination of $\mathrm{pH}$, carbon dioxide tension, base excess and standard bicarbonate in capillary blood. Scand. J. Clin. Lab. Invest., 12, 172-176.

Steele, T. W., and Edwards, K. D. G. (1971). Analgesic nephropathy: changes in various parameters of renal function following cessation of analgesic abuse. Med. J. Aust., 1, 181-187.

Steele, T. W., Györy, A. Z., and Edwards, K. D. G. (1969). Renal function in analgesic nephropathy. Brit. med. J., 2, 213-216.

Tannen, R. L. (1971). The response of normal subjects to the short ammonium chloride test: the modifying influence of renal ammonia production. Clin. Sci., 41, 583-595.

Wrong, O., and Davies, H. E. F. (1959). The excretion of acid in renal disease. Quart. J. Med., 28, 259-314. 